\title{
In vitro degradation and mineralization of strontium-substituted hydroxyapatite coating on magnesium alloy synthesized via hydrothermal route
}

\author{
Yue LI ${ }^{1}$, Sibo SHEN ${ }^{2}$, Lingjun ZHU ${ }^{3}$, Shu CAI ${ }^{1 \dagger}$, Yangyang JIANG ${ }^{1}$, Rui LING ${ }^{1}$, \\ Song JIANG', Yishu LIN ${ }^{1}$, Shaoshuai HUA ${ }^{1}$ and Guohua $\mathrm{XU}^{3 \text {; }}$ \\ ${ }^{1}$ Key Laboratory for Advanced Ceramics and Machining Technology of Ministry of Education, Tianjin University, \\ Tianjin 300072, China \\ ${ }^{2}$ College of Chemical Engineering, Hebei Normal University of Science and Technology, Qinhuangdao 066600, China \\ ${ }^{3}$ Department of Orthopedic Surgery, The spine surgical center, Changzheng Hospital, Second Military Medical University, \\ Shanghai 200003, China
}

\begin{abstract}
Magnesium (Mg) and its alloy as promising biodegradable orthopaedic implants have gained immense attention by virtue of their superior biocompatibility and mechanical compatibility. In order to increase the long-term corrosion resistance of $\mathrm{Mg}$ and its alloys in clinical application, in this work, a series of strontium-substituted hydroxyapatite (SrHA) coatings were constructed on Mg alloy via hydrothermal route. These SrHA coatings possessed bilayer structure with flower-like clusters as the surface layer and flat surface as the bottom layer. Coating III with $\mathrm{Sr} / \mathrm{Ca}$ molar ratio of 0.07 exhibited crack-free bottom layer and good interfacial adhesion, and its electrochemical corrosion resistance was higher than the counterparts. Moreover, this coating with high dissolution and rough surface rapidly induced SrHA mineralized layer formation, which gradually grew dense and thick, providing favorable long-term protection for $\mathrm{Mg}$ alloy. After immersion in simulated body fluid for 29 days, the average degradation rate of $\mathrm{Mg}$ alloy decreased to $0.17 \mathrm{mg} / \mathrm{day} \cdot \mathrm{cm}^{2}$. The present work demonstrated that this SrHA coating was a potential protective coating for Mg and Mg alloy implants.

(02019 The Ceramic Society of Japan. All rights reserved.
\end{abstract}

Key-words : Strontium-substituted hydroxyapatite coating, Magnesium alloy, Hydrothermal synthesis, In vitro degradation and mineralization, Corrosion resistance

\section{Introduction}

As one type of biodegradable metals, magnesium $(\mathrm{Mg})$ and its alloys have received immense attention due to their superior biocompatibility as well as mechanical compatibility. ${ }^{1{ }^{-4)}}$ In particular, $\mathrm{Mg}$ and its alloys have lower elastic modulus compared with the traditional implant metals (e.g., Ti, Co, Cr alloys), which can mitigate the stress shielding effect when acting as load-bearing implants. ${ }^{2)-4)}$ It is essential that $\mathrm{Mg}$ and its alloys maintain the mechanical integrity in physiological environment over a timescale of 12-18 weeks before totally degrading and replace by the regenerative bone tissues. ${ }^{5), 6)}$ However, $\mathrm{Mg}$ and its alloys are prone to be corroded in human body fluid containing $\mathrm{Cl}^{-}$, leading to destruction of mechanical integrity, excessive hydrogen release, local alkalization, and eventually failure of the bone repair. ${ }^{7)-9)}$ In the initial

Corresponding author: S. Cai; E-mail: caishu@tju.edu.cn

¥ Corresponding author: G. Xu; E-mail: xuguohuamail@ 163.com period of implantation, the degradation rate of $\mathrm{Mg}$ and its alloys has a momentous influence on the newly formed bone tissue. Therefore, most researches focus on enhancing the long-term corrosion resistance of $\mathrm{Mg}$ and its alloys, targeting as a class of temporary orthopaedic implants.

For this purpose, several strategies have been proposed, e.g., composition and structural optimization of $\mathrm{Mg}$ alloys ${ }^{10)}$ and surface modification. ${ }^{11)-13)}$ Specifically, using biocompatible coatings has been considered as one of the most effective surface modification methods, which can exert the physical barrier effect for $\mathrm{Mg}$ and its alloys while preserving the intrinsic advantages of substrates. ${ }^{14)}$ Meanwhile, the surface composition and microstructure of the coatings can influence the interaction between the implants and bone tissues, thus affecting the long-term osseointegration. To date, various coating methods, e.g., micro-arc oxidation, ${ }^{15)}$ electrodeposition, ${ }^{16)}$ sol-gel, ${ }^{17)}$ pulsed-laser deposition, ${ }^{18)}$ hydrothermal, ${ }^{19)}$ and chemical conversion ${ }^{20)}$ have been developed for $\mathrm{Mg}$ and its alloys. Among these methods, hydrothermal synthesis is preferred because of simple processing and low treatment temperature. ${ }^{19), 21)-23 \text { ) }}$ 
In addition, hydrothermal synthesis can facilitate ion exchange for the obtained coatings, e.g., substitution of $\mathrm{Ca}^{2+}$ with $\mathrm{Sr}^{2+}$ in hydroxyapatite $\left[\mathrm{Ca}_{10}\left(\mathrm{PO}_{4}\right)_{6}(\mathrm{OH})_{2}, \mathrm{HA}\right]$ to gain $\mathrm{Sr}^{2+}$ substituted HA (SrHA). Moreover, it is expedient to coat 3-dimensional substrates and increase coating mechanical strength. Zhang et al. ${ }^{23)}$ developed a crack-free $\mathrm{HA} /$ phytic acid hybrid coating on $\mathrm{Mg}$ alloy via chemical conversion and hydrothermal route; the bond strength of the coating reached $24.3 \pm 1.7 \mathrm{MPa}$.

It is worth noting that coating solubility is a key factor for their protection effect for $\mathrm{Mg}$ and its alloys. Compared with crystalline HA, the absorbable and non-stoichiometric calcium-deficient apatite is more suitable as protective coatings for the following two aspects. First, high solubility implies high mineralization capacity, which promotes mineralized layer formation to offer long-term protection for $\mathrm{Mg}$ and its alloys. Second, excellent biological performance is beneficial for osteoconduction and osteoinduction. Specifically, SrHA is deemed as one type of desired material as protective coatings with high bioactivity and absorbable interface. ${ }^{24)}$ Previous studies have shown that strontium is useful for improving the mineralization and bone-bonding ability when $\mathrm{Sr}^{2+}$ substitution amount in HA is 3-7 at \%. ${ }^{18), 25)}$ Besides, SrHA can inhibit bone resorption by osteoclasts, also promote osteoblast replication and bone formation. ${ }^{26)-28)}$ Inspired by the above breakthroughs, in this work, SrHA coatings were constructed on $\mathrm{Mg}$ alloy via a hydrothermal route to enhance its long-term corrosion resistance. The composition and structure, electrochemical property, in vitro degradation and mineralization of $\mathrm{Mg}$ alloy with SrHA coatings were investigated.

\section{Materials and methods}

\subsection{Sample preparation}

AZ31 Mg alloy plates (wt \%: 3\% Al, 1\% Zn, 0.2\% Mn, $<0.005 \% \mathrm{Fe}$ ) were used as the substrates with the dimension of $10 \mathrm{~mm} \times 10 \mathrm{~mm} \times 2 \mathrm{~mm}$. Firstly, surface of the substrates was ground using carborundum papers (grit \#800, \#1500 and \#2000). Then, the substrates were ultrasonically treated in deionized water and alcohol for 10 min, respectively. Next, the substrates were immersed in $1.5 \mathrm{M}$ sodium hydrate solutions at $80^{\circ} \mathrm{C}$ for $1 \mathrm{~h}$. Finally, the substrates were rinsed with deionized water and dried at $37^{\circ} \mathrm{C}$.

Four kinds of coating solutions with different $\mathrm{Sr} / \mathrm{Ca}$ molar ratios were prepared. Firstly, strontium nitrate $\left[\mathrm{Sr}\left(\mathrm{NO}_{3}\right)_{2}\right]$ and calcium nitrate tetrahydrate $\left[\mathrm{Ca}\left(\mathrm{NO}_{3}\right)_{2}\right.$. $4 \mathrm{H}_{2} \mathrm{O}$ ] were dissolved into deionized water with magnetic stirring; sodium phosphate dibasic dodecahydrate $\left(\mathrm{Na}_{2} \mathrm{HPO}_{4} \cdot 12 \mathrm{H}_{2} \mathrm{O}\right)$ was dissolved into deionized water with magnetic stirring; $\mathrm{Na}_{2} \mathrm{HPO}_{4}$ solution was added dropwise into $\mathrm{Sr}\left(\mathrm{NO}_{3}\right)_{2}$ and $\mathrm{Ca}\left(\mathrm{NO}_{3}\right)_{2}$ mixed solution with magnetic stirring; $\mathrm{pH}$ value of the mixed solution was adjusted to 6.3 with $1 \mathrm{M}$ nitric acid (coating solutions). The total concentration of $\mathrm{Ca}^{2+}$ and $\mathrm{Sr}^{2+}$ in the coating solutions was $3.21 \mathrm{mM}$ and that of $\mathrm{PO}_{4}{ }^{3-}$ was $1.40 \mathrm{mM}$. In addition, $\mathrm{Sr} / \mathrm{Ca}$ molar ratios of the coating solutions were set as $0,0.05,0.10$ and 0.15 , respectively. Then, alkaline- treated substrates were placed into an autoclave containing $30 \mathrm{~mL}$ one kind of coating solution, and hydrothermally treated at $100^{\circ} \mathrm{C}$ for $3 \mathrm{~h}$ with the heating rate of $2^{\circ} \mathrm{C} / \mathrm{min}$. The obtained coatings using coating solutions with $\mathrm{Sr} / \mathrm{Ca}$ molar ratio of $0,0.05,0.10$ and 0.15 were denoted as Coating I, Coating II, Coating III and Coating IV, respectively. Finally, the obtained coatings were cleaned with deionized water by 5 times and dried with air.

\subsection{Coating characterization}

The phase, surface and cross-section morphologies and chemical composition of the obtained coatings were investigated using X-ray diffraction (XRD, D/Max-2500 Rigaku, Japan), field-emission scanning electron microscope (FE-SEM, S4800 Hitachi, Japan) equipped with energy dispersive spectrum (EDS, 7401 Oxford, UK).

\subsection{Electrochemical measurement}

The electrochemical properties of the samples were measured via potentiodynamic polarization and electrochemical impedance spectra (EIS) using a three-electrode cell containing simulated body fluid (SBF) and electrochemical workstation $\left(\mathrm{CHI} 660 \mathrm{C}\right.$, China) at $37^{\circ} \mathrm{C}$. The electrochemical tests were replicated five times to ensure reproducibility.

\subsection{Immersion test}

In vitro immersion test was carried out in $\mathrm{SBF}(\mathrm{pH}=$ 7.4) at $37 \pm 0.5^{\circ} \mathrm{C}$ using an incubator (FYL-YS-150L, Beijing Fuyi Instrument Co., LTD, China). The applied SBF was developed by Kokubo et al. in 1991 and named as Corrected SBF, whose ion concentrations were shown in Table S1. ${ }^{29), 30)}$ The volume of SBF was determined based on the surface area of samples of $50 \mathrm{~mL} / \mathrm{cm}^{2}$ according to ASTM-G31-72. ${ }^{31)}$ SBF was renewed every 2 days. The $\mathrm{pH}$ value of SBF was recorded using $\mathrm{pH}$ meter (PHS3E, Leici, China). The concentrations of $\mathrm{Sr}, \mathrm{Ca}$ and $\mathrm{P}$ elements of SBF were monitored by inductively coupled plasma optical emission spectrometer (ICP-OES, VISTAMPX, Varian, USA). Mg alloy with Coating III immersed in SBF for different times were taken out and characterized by XRD, SEM and EIS test. After immersion test, Mg alloy with Coating III was immersed in dilute chromic acid solution to remove the mineralized products and corrosion products, which was the standard method for metal corrosion test. ${ }^{8)}$ The weight loss of $\mathrm{Mg}$ alloy is determined by Eq. (1):

$$
W L=\left(w_{0}-w_{n}\right) / A
$$

where $W L$ is the weight loss, $w_{0}$ is the initial weight $(\mathrm{mg})$ of $\mathrm{Mg}$ alloy; $w_{n}$ is the weight $(\mathrm{mg})$ of $\mathrm{Mg}$ alloy after immersion in SBF for $n$ days; $A$ is the initial contact area $\left(\mathrm{cm}^{2}\right)$ between the sample and SBF. Degradation rate of $\mathrm{Mg}$ alloy is evaluated by Eq. (2):

$$
D R_{n}=\left(w_{n-1}-w_{n}\right) / A
$$

where $D R_{n}$ is the degradation rate of $\mathrm{Mg}$ alloy during immersion in SBF at $n$ day. 


\section{Results and discussion}

\subsection{Characterization of the coatings}

Protection effect of the coatings for $\mathrm{Mg}$ and its alloy is strongly based on their composition and structure. ${ }^{32)}$ XRD patterns of the coatings synthesized via the hydrothermal route are shown in Fig. 1. All XRD patterns possessed HA diffraction peaks (JCPDS no. 09-0432) and $\alpha$-Mg diffraction peaks (JCPDS no. 89-7195) belonging to the substrate. Moreover, with the increasing of $\mathrm{Sr}^{2+}$ content in the coating solutions, $2 \theta$ for (002) peak of HA crystal first decreased from $26.174^{\circ}$ for Coating I to $25.880^{\circ}$ for Coating III, then increased to $26.057^{\circ}$ for Coating IV (Table 1). The change of lattice parameter of HA crystal demonstrated that $\mathrm{Sr}^{2+}$ was structurally incorporated into HA lattice during the hydrothermal synthesis. Bigi et al. ${ }^{33)}$ reported that $\mathrm{Sr}^{2+}$ could occupy both $\mathrm{Ca}^{2+}$ (I) site and $\mathrm{Ca}^{2+}$ (II) site in HA lattice. When the substitution amount

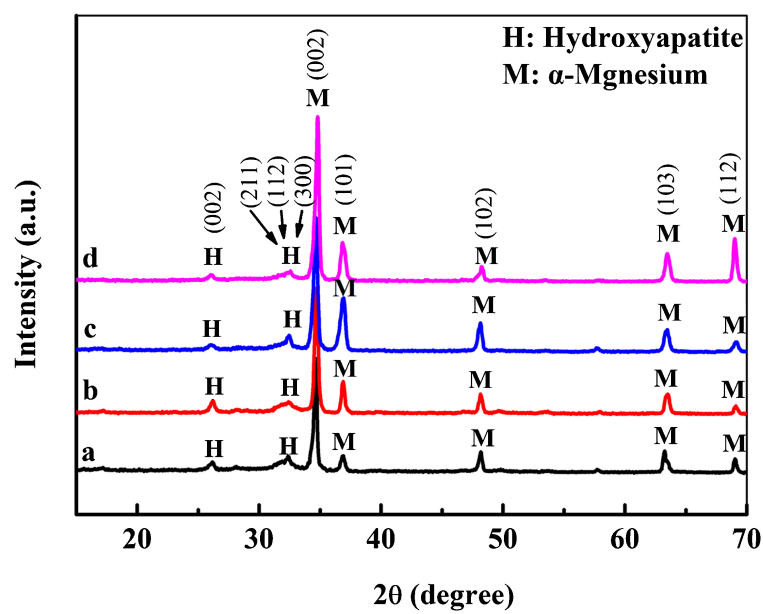

Fig. 1. XRD patterns of the obtained coatings: (a) Coating I, (b) Coating II, (c) Coating III and (d) Coating IV. of $\mathrm{Sr}^{2+}$ was low, $\mathrm{Sr}^{2+}$ preferred to occupy $\mathrm{Ca}^{2+}$ (I) site, leading to increasing of interplanar spacing of (002) facet for $\mathrm{Sr}^{2+}$ had bigger ionic diameter than $\mathrm{Ca}^{2+}$, which reflecting on that the XRD pattern was the shift of (002) peak to lower diffraction angle; however, in the case of larger $\mathrm{Sr}^{2+}$ substitution amount, $\mathrm{Sr}^{2+}$ tended to occupy $\mathrm{Ca}^{2+}$ (II) site to form a staggered equilateral triangle structure. It was suggested that with $\mathrm{Sr} / \mathrm{Ca}$ molar ratios of the coating solutions ranges between 0.10 and $0.15, \mathrm{Sr}^{2+}$ substituting position gradually changed from calcium (I) site to calcium (II) site in HA lattice. The above results indicated that HA coating (Coating I) and SrHA coatings (Coating II, Coating III and Coating IV) were successfully constructed on $\mathrm{Mg}$ alloy.

Surface morphologies of HA coating and SrHA coatings are displayed in Fig. 2. All the coatings exhibit similar bilayer structures with randomly scattered flower-like clusters as the surface layer and relative flat surface as the bottom layer [Figs. 2(a)-2(c) and 2(f)]. Specifically, the flower-like clusters for Coating III looked much denser than the three counterparts. Typical surface morphologies of the flower-like cluster and bottom layer are shown in Figs. 2(d) and 2(e), in which, it could be found that they both were constructed by nanoplates. Notably, there were some cracks on the surface of the bottom layers of Coating I, Coating II and Coating IV, however, Coating III demonstrated a crack-free bottom layer. Chemical compositions of the coatings are shown in Table 2. With the increasing of $\mathrm{Sr}$ content in the coating solutions, $\mathrm{Sr} / \mathrm{Ca}$ molar ratio of the coatings gradually increased from 0 for Coating I to 0.14 for Coating IV. It was suggested that $\mathrm{Sr}^{2+}$

Table 1. $2 \theta$ for (002) peak of HA crystal of the obtained coatings

\begin{tabular}{ccccc}
\hline Samples & Coating I & Coating II & Coating III & Coating IV \\
\hline $2 \theta$ (Degree) & 26.174 & 26.168 & 25.880 & 26.057 \\
\hline
\end{tabular}

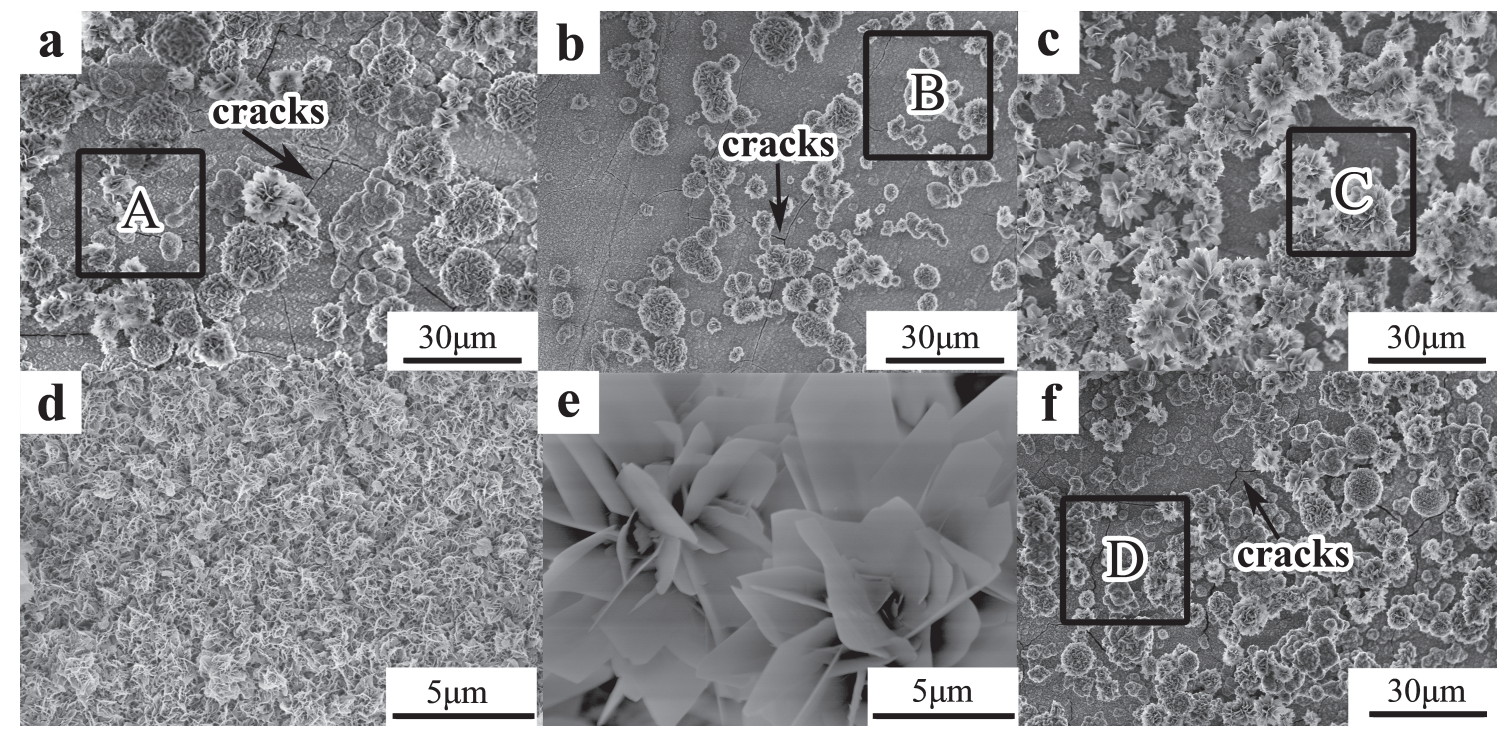

Fig. 2. Low-magnification SEM images of surface morphologies of the coatings: (a) Coating I, (b) Coating II,

(c) Coating III and (f) Coating IV. High-magnification SEM images of surface morphologies of Coating III:

(d) bottom layer and (e) surface layer. 
substitution amount in HA lattice influenced the integrity of the bottom layer of the coatings. In clinical application, integrity of protective coatings is an essential requirement for $\mathrm{Mg}$ and $\mathrm{Mg}$ alloy implants (e.g., bone stents and plates).

During this hydrothermal route, high temperature of $100^{\circ} \mathrm{C}$ enhanced the chemical driving force for SrHA nanoplates nucleation and growth, leading to rapid growth of the bottom layer, which might generate interfacial residual stress. ${ }^{34), 35)}$ When the residual stress exceeded the cohesion strength of the coatings, surface cracks appeared on the bottom layer, e.g., Coating I (average width of the cracks was $0.3 \mu \mathrm{m}$ ) and Coating II (average width of the cracks was $0.2 \mu \mathrm{m}$ ) [Figs. 2(a) and 2(b)]. However, Coating III exhibited a crack-free bottom layer [Fig. 2(c)], which was probably ascribed to two factors: first, $\mathrm{Sr}^{2+}$ substitution in HA lattice increased the crystal size, ${ }^{36)}$ second, $\mathrm{Sr}^{2+}$ substitution in HA lattice promoted oriented growth to the $c$-axis of $\mathrm{HA},{ }^{37)}$ which was conductive to obtain integral crystal. Both the two factors facilitated the growth of SrHA coating, which might mitigate the residual stress. As for Coating IV, the staggered equilateral triangle structure due to occupation of $\mathrm{Sr}^{2+}$ at $\mathrm{Ca}^{2+}$ (II) site was believed to enhance the residual stress, so cracks also existed [Fig. 2(f)].

In addition to coating integrity, interfacial adhesion between the coatings and substrates is another critical factor affecting the protection effect. As shown in Fig. 3, the cross-sectional morphology of coating III illustrated good adhesion without any cracks, which was beneficial to avoid the detachment during the clinical application. Moreover, the thickness of Coating III was about $4.5 \mu \mathrm{m}$. Thus favorable protection effect of Coating III for $\mathrm{Mg}$ alloy could be anticipated.

Table 2. EDS data (at.\%) of Areas A, B, C and D in Fig. 2

\begin{tabular}{cccccccl}
\hline Eample & $\mathrm{Ca}$ & $\mathrm{Sr}$ & \multicolumn{1}{c}{$\mathrm{P}$} & $\mathrm{O}$ & $\mathrm{Mg}$ & $\mathrm{C}$ & $\mathrm{Sr} / \mathrm{Ca}$ \\
\hline Coating I & 14.75 & 0 & 8.98 & 52.93 & 2.08 & 20.99 & 0 \\
Coating II & 13.77 & 0.78 & 8.93 & 50.75 & 2.04 & 23.73 & 0.06 \\
Coating III & 21.15 & 1.38 & 12.18 & 44.32 & 1.01 & 19.96 & 0.07 \\
Coating IV & 11.99 & 1.70 & 8.56 & 50.49 & 2.01 & 25.24 & 0.14 \\
\hline
\end{tabular}

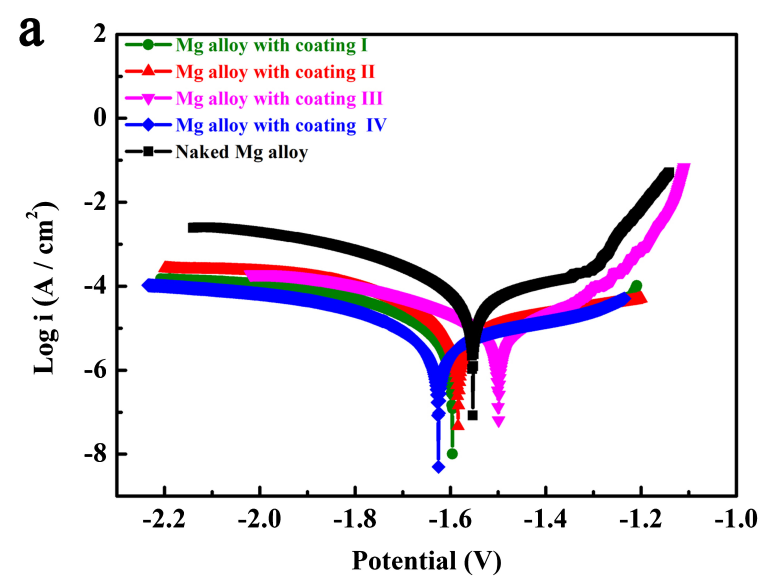

\subsection{Electrochemical properties of the samples}

Electrochemical properties of the coated and naked $\mathrm{Mg}$ alloys are depicted in Fig. 4. Corrosion current density $\left(i_{\text {corr }}\right)$ and corrosion potential $\left(E_{\text {corr }}\right)$ determined by Tafel extrapolation method from the potentiodynamic polarization curves are shown in Table S2. High $E_{\text {corr }}$ and low $i_{\text {corr }}$ meant that a sample had a low corrosion rate. ${ }^{38)}$ Among the five samples, $\mathrm{Mg}$ alloy with Coating III exhibited the highest $E_{\text {corr }}$ of $-1.49 \mathrm{~V}_{\mathrm{SCE}}$ and lowest $i_{\text {corr }}$ of 2.04 $\mu \mathrm{A} / \mathrm{cm}^{2}$. Additionally, Nyquist plots of the samples in Fig. 4(b) illustrated that Mg alloy with Coating III had the highest impedance of $14 \mathrm{Kohm} \cdot \mathrm{cm}^{2}$. The electrochemical properties of the samples demonstrated that Coating III with crack-free bottom layer and relative dense surface layer endowed $\mathrm{Mg}$ alloy with the favorable short-term protection.

\subsection{In vitro degradation and mineralization of the samples}

In order to explore the long-term protection effect of Coating III for $\mathrm{Mg}$ alloy, $\mathrm{Mg}$ alloy with Coating III (experimental group), $\mathrm{Mg}$ alloy with Coating I (control group)

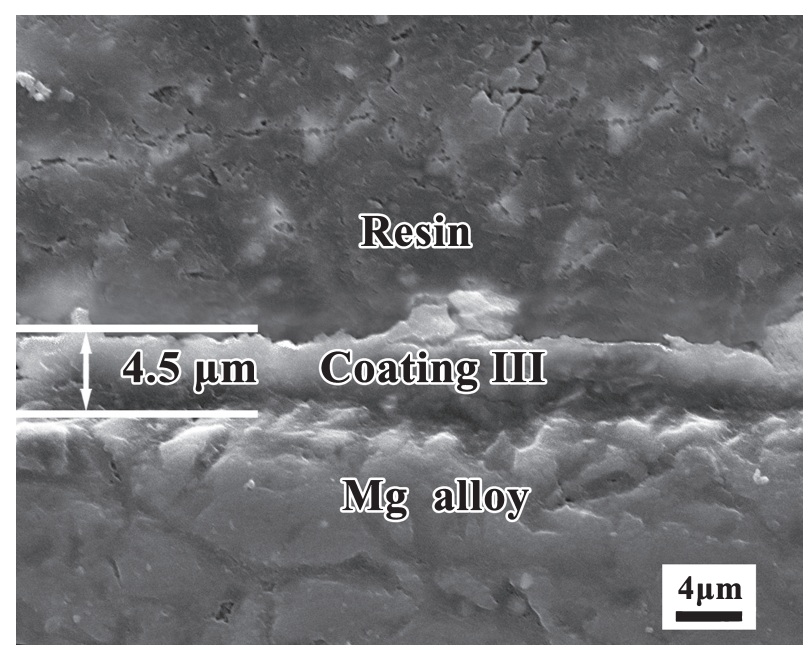

Fig. 3. SEM image of cross-section morphology of Coating III.

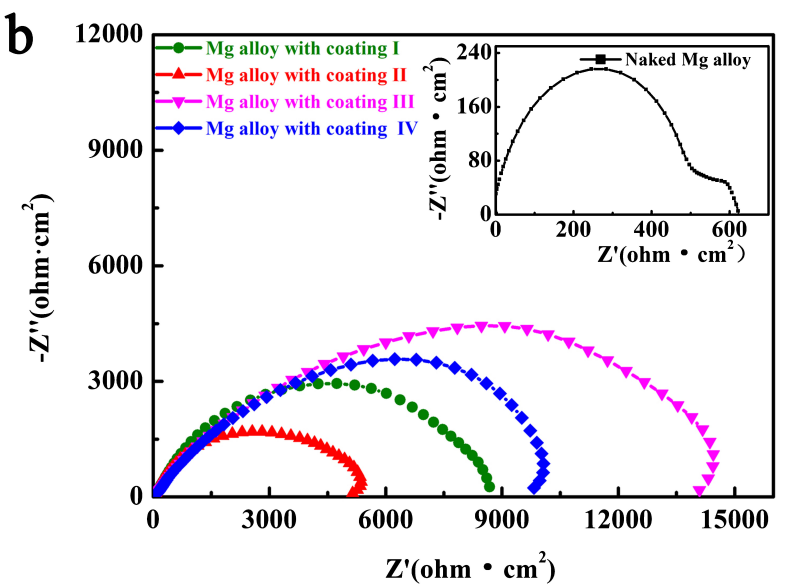

Fig. 4. Electrochemical properties of the samples: (a) potentiodynamic polarization curves; (b) Nyquist plots. 

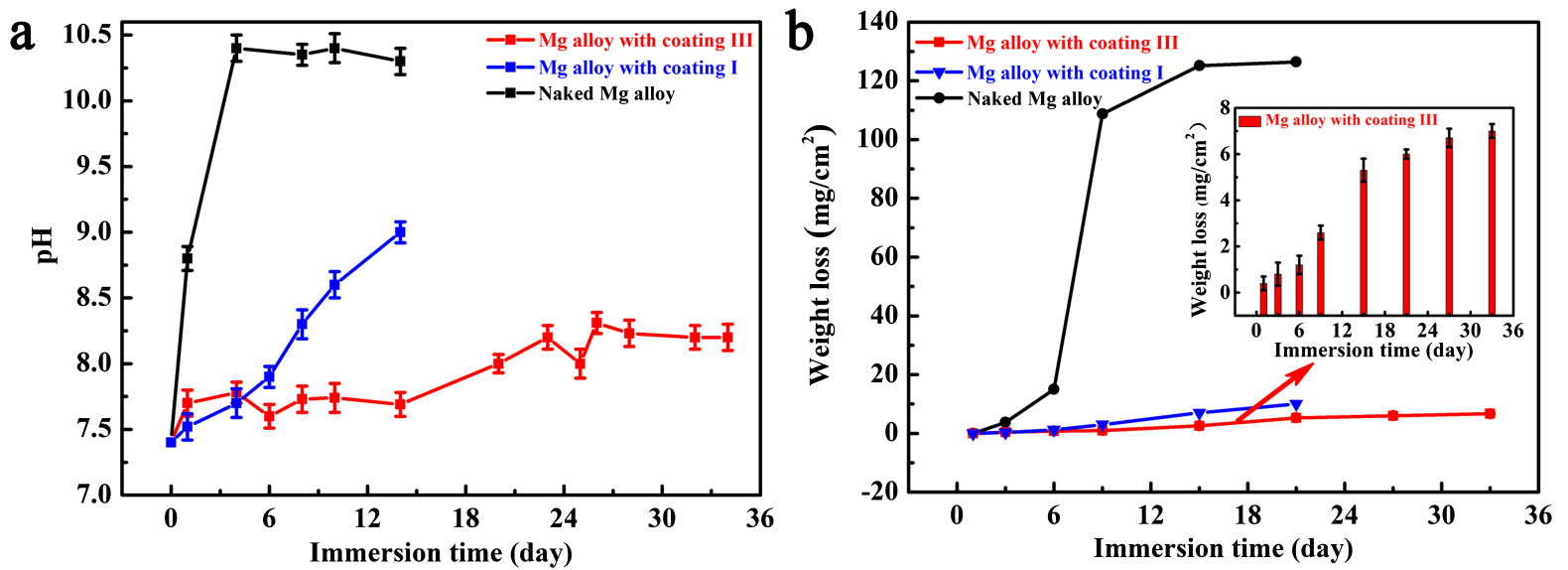

Fig. 5. (a) $\mathrm{pH}$ value of SBF immersing naked and coated $\mathrm{Mg}$ alloys after different times. (b) Weight losses of naked and coated Mg alloys.

Table 3. Sr element concentration of the SBF immersing $\mathrm{Mg}$ alloy with Coating III for different times

\begin{tabular}{ccccccc}
\hline Time & 1 day 3 days 9 days 21 days 27 days 33 days \\
\hline Sr concentration $(\mathrm{ppm})$ & 0.513 & 0.482 & 0.444 & 0.375 & 0.293 & 0.235 \\
\hline
\end{tabular}

and naked $\mathrm{Mg}$ alloy (control group) were selected for SBF immersion test. Both $\mathrm{Mg}$ alloy corrosion and coating dissolution could cause the rising of $\mathrm{pH}$ value of $\mathrm{SBF}^{39), 40)}$ As Fig. 5(a) shows, $\mathrm{pH}$ value of SBF immersing naked $\mathrm{Mg}$ alloy displayed a dramatic increase to 10.4 after 4 days because of the rapid corrosion of $\mathrm{Mg}$ alloy. However, $\mathrm{pH}$ value of SBF immersing Mg alloy with Coating I gradually went up to 9.0 after 14 days. By contrast, $\mathrm{pH}$ value of SBF immersing Mg alloy with Coating III increased to 7.8 in the initial 4 days, then increased to 8.3 after 26 days and finally stabilized at 8.2 , displaying a relative slight fluctuation. Moreover, during SBF immersion process, weight losses of the samples were measured and the results are shown in Fig. 5(b). Weight loss of naked $\mathrm{Mg}$ alloy reached to $126.4 \mathrm{mg} / \mathrm{cm}^{2}$ after 21 days, however, that of $\mathrm{Mg}$ alloy with Coating III was $6.3 \mathrm{mg} / \mathrm{cm}^{2}$ after 33 days, indicating that Coating III effectively retarded the degradation of $\mathrm{Mg}$ alloy. Moreover, compared with Coating I (HA), Coating III (SrHA) offered better long-term protection effect for $\mathrm{Mg}$ alloy. In addition, dissolution of Coating III was studied by measuring $\mathrm{Sr}$ element concentration of SBF. With the prolonging of immersion time, Sr concentration of SBF exhibited a downward trend (Table 3). Notably, after 33 days' immersion, $\mathrm{Sr}$ concentration still remained as $0.235 \mathrm{ppm}$, implying the controlled-releasing of $\mathrm{Sr}$ element from this SrHA coating. Importantly, $\mathrm{Sr}$ in SBF was reported to improve the mineralization capacity. ${ }^{41)}$

In order to analyze the mineralized layer formed on Coating III, phase and surface morphologies of $\mathrm{Mg}$ alloy with Coating III after immersion in SBF for different times were characterized. As Fig. 6 shows, after immersion for 3 days, XRD pattern of $\mathrm{Mg}$ alloy with Coating III possessed HA diffraction peaks (JCPDS No. 09-0432). Moreover, the $2 \theta$ for $(002)$ peak of HA crystal was $25.991^{\circ}$ ( $2 \theta$ for

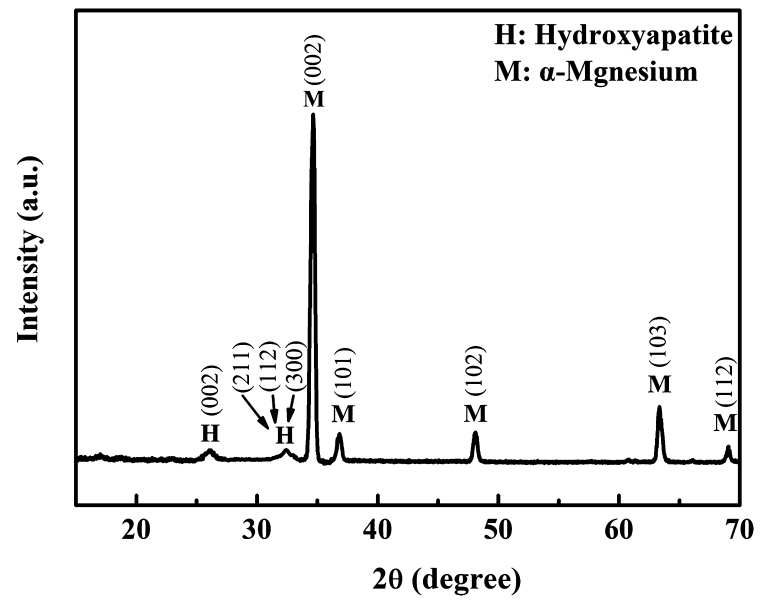

Fig. 6. XRD pattern of $\mathrm{Mg}$ alloy with Coating III after immersion in SBF for 3 days.

(002) peak of HA crystal of Coating I was 26.174), implying that the formed mineralized layer was singlephase SrHA. Besides, the full width at half maxima (FWHM) for (002) peak of Coating III after 3 days' immersion and SrHA mineralized layer was $0.706^{\circ}$, higher than that of Coating III before immersion $\left(0.327^{\circ}\right)$, suggesting that SrHA mineralized layer had smaller crystal size. In parallel, concentrations of both $\mathrm{Ca}$ and $\mathrm{P}$ elements of SBF immersing $\mathrm{Mg}$ alloy with coating III for 1 day and 3 days were highly lower than those of the fresh SBF (Table S3), which were consumed to rapidly generate SrHA mineralized layer on Coating III.

Surface morphologies of $\mathrm{Mg}$ alloy with Coating III after immersion in SBF for different times are depicted in Fig. 7. After 1 day's immersion, some corrosion holes occurred on the bottom layer [Figs. 7(a) and 7(b)], which was related to the high solubility of this SrHA coating ${ }^{28)}$ however, the flower-like clusters on surface layer turned into spherical clusters with compact architecture [Fig. 7(c)], suggesting high mineralization capacity of SrHA coating. Meanwhile, the average degradation rate of $\mathrm{Mg}$ alloy was relatively high $\left(0.40 \mathrm{mg} / \mathrm{day}^{\cdot} \mathrm{cm}^{2}\right)$ (Fig. S1). 


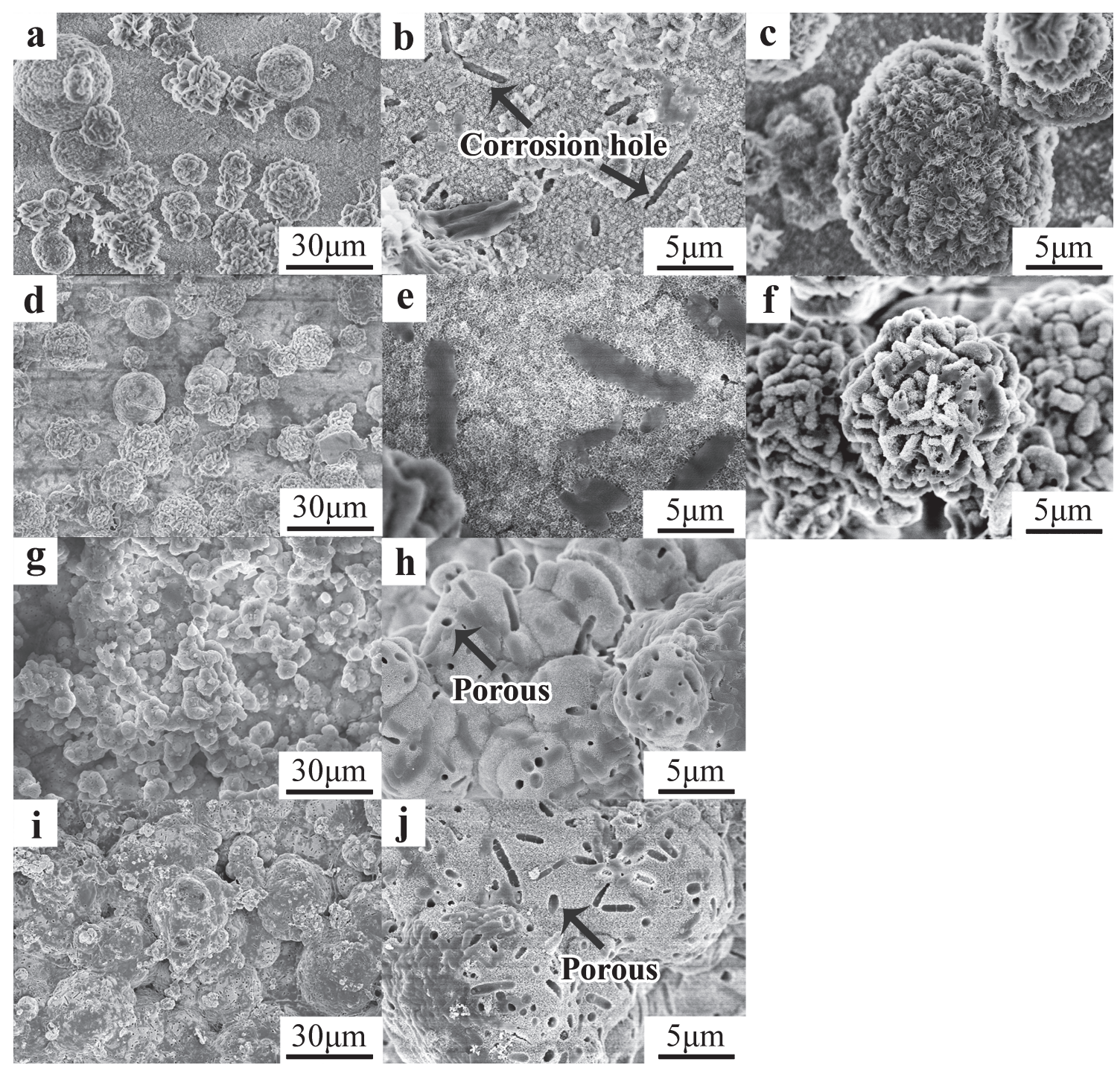

Fig. 7. Low- and high-magnification SEM images of surface morphologies of $\mathrm{Mg}$ alloy with Coating III after immersion in SBF for different times: (a-c) 1 day, (d-f) 3 days, $(g, h) 9$ days and (i, j) 33 days.

After 3 days' immersion, the formed mineralized layer covered the corrosion holes on the bottom layer [Figs. 7(d) and $7(\mathrm{e})]$, however, the crystals of the spherical clusters on the surface layer grew bigger [Fig. 7(f)], so the average degradation rate of $\mathrm{Mg}$ alloy decreased to 0.18 $\mathrm{mg} /$ day ${ }^{\circ} \mathrm{cm}^{2}$ (Fig. S1). After 9 days' immersion, the mineralized layer totally covered the original protective coating, revealing a structure consisting of porous hemispherical particles [Figs. 7(g) and 7(h)]. After 33 days' immersion, mineralized layer grew much denser [Figs. 7(i) and $7(\mathrm{j})$ ], so the average degradation rate of $\mathrm{Mg}$ alloy decreased to $0.17 \mathrm{mg} /$ day $\cdot \mathrm{cm}^{2}$. High dissolution and rough surface with bilayer structure of Coating III had outstanding mineralization capacity, leading the mineralized layer to gradually grow thick and dense, which was supposed to effectively isolate the underlying $\mathrm{Mg}$ alloy and corrosive fluid, so exerted favorable long-term protection effect. Notably, after 13 days' immersion, the average degradation rate of $\mathrm{Mg}$ alloy began decreasing (Fig. S1). Moreover, the corresponding impedance of $\mathrm{Mg}$ alloy with
Coating III after immersion for different times initially decreased from 14 to $0.8 \mathrm{Kohm} \cdot \mathrm{cm}^{2}$ after 12 days, and then increased to $5.8 \mathrm{Kohm} \cdot \mathrm{cm}^{2}$ after 33 days (Fig. S2), this change was well consistent with the average degradation rate of $\mathrm{Mg}$ alloy as well as the structural evolution of mineralized layer. Therefore, Coating III and the continuously formed SrHA mineralized layer enhanced the long-term corrosion resistance of $\mathrm{Mg}$ alloy.

\section{Conclusions}

In this work, a series of SrHA coatings were constructed on $\mathrm{Mg}$ alloy via a hydrothermal route to enhance its longterm corrosion resistance. These SrHA coatings possessed bilayer structure with flower-like clusters as the surface layer and flat surface as the bottom layer. When $\mathrm{Sr} / \mathrm{Ca}$ molar ratio of the coating solution was 0.10 , the obtained SrHA coating, i.e., Coating III, exhibited a crack-free bottom layer. Electrochemical test showed that $\mathrm{Mg}$ alloy with Coating III had higher corrosion resistance than the counterparts. Immersion test revealed that Coating III 
could rapidly induce SrHA mineralized layer formation, which gradually grew dense and thick, endowing $\mathrm{Mg}$ alloy with favorable long-term protection. After immersion in SBF for 29 days, the average degradation rate of $\mathrm{Mg}$ alloy decreased to $0.17 \mathrm{mg} /$ day $\cdot \mathrm{cm}^{2}$. The present work potentially provides a new avenue of protective coating design for $\mathrm{Mg}$ and $\mathrm{Mg}$ alloy for orthopaedic application.

Acknowledgments Authors acknowledge the financial support by National Nature Science Foundation of China (Grant No. 51872197, 51572186 and 81271954), Tianjin Natural Science Foundation (Grant No. 15JCYBJC47500) and Shanghai Committee of Science and Technology (Grant No. 16XD1424700 and 15411951000). The authors acknowledge Mr. Chang Lin for his help in the experimental work via Tianjin-Hainan university innovation fund cooperation project (Grant No. 2017XZC-0104). The authors also appreciate the instrumental assistance from Hebei Key Laboratory of Active Components and Functions in Natural Products (under planning).

\section{References}

1) H. Hornberger, S. Virtanen and A. R. Boccaccini, Acta Biomater, 8, 2442-2455 (2012).

2) X. Y. Ye, G. H. Xu, S. Cai, Y. Zhu and H. Hu, J. Mater. Sci., 47, 3763-3769 (2011).

3) H. Ishizawa and M. Oginoh, J. Mater. Sci., 34, 58935898 (1999).

4) A. Srinivasan, S. K. Shin and N. Rajendran, $R S C A d v$,, 6, 49910-49922 (2016).

5) M. P. Staiger, A. M. Pietak and J. Huadmai, Biomaterials, 27, 1728-1734 (2006).

6) F. Witte, V. Kaese, H. Haferkamp, E. Switzer, A. MeyerLindenberg and C. J. Wirth, Biomaterials, 26, 35573563 (2005).

7) R. Maurya, A. R. Siddiqui and K. Balani, Surf. Coat. Tech., 325, 65-74 (2007).

8) S. B. Shen, S. Cai, M. Zhang, G. H. Xu, Y. Li, R. Ling and X. D. Wu, Mater. Lett., 159, 146-149 (2015).

9) M. Razavi, M. Fathi, O. Savabi, B. H. Beni, S. M. Razavi, D. Vashaee and L. Tayebi, Appl. Surf. Sci., 288, 130-137 (2014).

10) G. S. Wu, J. M. Ibrahim and P. K. Chu, Surf. Coat. Tech., 233, 2-12 (2013).

11) H. Zhao, S. Cai, Z. T. Ding, M. Zhang, Y. Li and G. H. $\mathrm{Xu}, R S C$ Adv. , 5, 24586-24590 (2015).

12) W. Xia, C. Lindahl, J. Lausmaa, P. Borchardt, A. Ballo, P. Thomsen and H. Engqvist, Acta Biomater., 6, 15911600 (2010).

13) W. Zhang, Y. Shen, H. Pan, K. Lin, X. Liu, B. Darvell, W. Lu, J. Chang, L. Deng, D. Wang and W. Huang, Acta Biomater., 7, 800-808 (2011).

14) J. L. Wang, J. Tang, P. Zhang, Y. Li, J. Wang, Y. X. Lai and L. Qin, J. Biomed. Mater. Res. B, 100B, 1691-1701 (2012).

15) K. H. Nan, T. Wu, J. H. Chen, S. Jiang, Y. Huang and G. X. Pei, Mater. Sci. Eng., C, 29, 1554-1558 (2009).

16) Y. W. Song, D. Y. Shan and E. H. Han, Mater. Lett., 62,
3276-3279 (2008).

17) A. Balamurugan, G. Balossier, P. Torres, J. Michel and J. M. F. Ferreira, Mater. Sci. Eng., C, 29, 1006-1009 (2009).

18) C. Capuccini, P. Torricelli, F. Sim, E. Boanini, C. Ristoscu, B. Bracci, G. Socol, M. Fini, I. N. Mihailescu and A. Bigi, Acta Biomater., 4, 1885-1893 (2008).

19) D. Song, G. Guo, J. Jiang, L. W. Jiang, A. B. Zhang, X. L. Ma, J. Q. Ma and Z. J. Cheng, Prog. Nat. SciMater., 26, 590-599 (2016).

20) J. Y. Han, Z. T. Yu and L. Zhou, Appl. Surf. Sci., 255, 455-458 (2008)

21) S. H. Wang, C. W. Yang and T. M. Lee, Ind. Eng. Chem. Res., 55, 5207-5215 (2016).

22) A. Abdal-hay, C. I. Kim and J. K. Lim, Ceram. Int., 40, 4995-5000 (2014).

23) M. Zhang, S. Cai, S. B. Shen, G. H. Xu, Y. Li, R. Ling and X. D. Wu, J. Alloy. Compd., 658, 649-656 (2016).

24) E. Boanini, M. Gazzano and A. Bigi, Acta Biomater., 6, 1882-1894 (2010).

25) A. R. Boyd, L. Rutledge, L. D. Randolph and J. B. Meenan, Mat. Sci. Eng. C-Mater., 46, 290-300 (2015).

26) W. Huang, B. Xu, W. Z. Yang, K. G. Zhang, Y. Chen, X. S. Yin, Y. Liu, Z. Y. Ni and F. Pei, Surf. Coat. Tech., 326, 270-280 (2017).

27) L. Li, X. Lu, Y. Z. Meng and C. M. Weyant, J. Mater. Sci.-Mater. M., 23, 2359-2368 (2012).

28) M. Supova, Ceram. Int., 41, 9203-9231 (2015)

29) T. Kokubo, Biomaterials, 12, 155-163 (1991).

30) T. Kokubo and H. Takadama, Biomaterials, 27, 29072915 (2006).

31) Standard Practice for Laboratory Immersion Corrosion Testing of Metals, G31, Annual Book of ASTM Standards Philadelphia, ASTM, Part 72 (2004).

32) N. Yu, S. Cai, F. W. Wang, F. Y. Zhang, R. Ling, Y. Li, Y. Y. Jiang and G. H. Xu, Ceram. Int., 43, 2495-2503 (2017).

33) A. Bigi, E. Boanini, C. Capuccini and M. Gazzano, Inorg. Chim. Acta, 360, 1009-1016 (2007).

34) G. H. Guo, D. Song, J. H. Jiang, A. B. Ma, L. W. Zhang and C. Li, Metals, 6, 44 (2016).

$35)$ S. B. Shen, S. Cai, X. G. Bao, P. Xu, Y. Li, S. Jiang and G. H. Xu, Chem. Eng. J., 339, 7-13 (2018).

36) Z. Y. Li, W. M. Lam, C. Yang, B. Xu, G. X. Ni, S. A. Abbah, K. M. C. Cheung, K. D. K. Luk and W. W. Lu, Biomaterials, 28, 1452-1460 (2007).

37) A. Bigi, G. Falini, M. Gazzano, N. Roveri and E. Tedesco, Mater. Sci. Forum, 814, 278-281 (1998).

38) H. Tang, T. Wu and W. Hong, J. Alloy. Compd., 698, 643-653 (2017).

39) M. P. Staiger, A. M. Pietak, J. Huadmai and G. Dias, Biomaterials, 27, 1728-1734 (2006).

40) F. Witte, N. Hort, C. Vogt, S. Cohen, K. U. Kainer, R. Willumeit and F. Feyerabend, Mater. Sci., 12, 63-72 (2008).

41) W. B. Zhang, Y. H. Shen, H. B. Pan, K. L. Lin, X. G. Liu, B. W. Darvell, W. W. Lu, J. Chang, L. F. Deng, D. P. Wang and W. H. Huang, Acta Biomater., 7, 800808 (2011). 